\title{
Towards comprehensive and transparent reporting: context-specific additions to the ICF taxonomy for medical evaluations of work capacity involving claimants with chronic widespread pain and low back pain
}

\author{
Urban Schwegler ${ }^{1,2^{*}}$, Jessica Anner ${ }^{3}$, Andrea Glässel ${ }^{1}$, Mirjam Brach$^{1}$, Wout De Boer ${ }^{3}$, Alarcos Cieza ${ }^{4}$ \\ and Bruno Trezzini'
}

\begin{abstract}
Background: Medical evaluations of work capacity provide key information for decisions on a claimant's eligibility for disability benefits. In recent years, the evaluations have been increasingly criticized for low transparency and poor standardization. The International Classification of Functioning, Disability and Health (ICF) provides a comprehensive spectrum of categories for reporting functioning and its determinants in terms of impairments and contextual factors and could facilitate transparent and standardized documentation of medical evaluations of work capacity. However, the comprehensiveness of the ICF taxonomy in this particular context has not been empirically examined. In this study, we wanted to identify potential context-specific additions to the ICF for its application in medical evaluations of work capacity involving chronic widespread pain (CWP) and low back pain (LBP).
\end{abstract}

Methods: A retrospective content analysis of Swiss medical reports was conducted by using the ICF for data coding. Concepts not appropriately classifiable with ICF categories were labeled as specification categories (i.e. context-specific additions) and were assigned to predefined specification areas (i.e. precision, coverage, personal factors, and broad concepts). Relevant specification categories for medical evaluations of work capacity involving CWP and LBP were determined by calculating their relative frequency across reports and setting a relevance threshold.

Results: Forty-three specification categories for CWP and fifty-two for LBP reports passed the threshold. In both groups of reports, precision was the most frequent specification area, followed by personal factors.

Conclusions: The ICF taxonomy represents a universally applicable standard for reporting health and functioning information. However, when applying the ICF for comprehensive and transparent reporting in medical evaluations of work capacity involving CWP and LBP context-specific additions are needed. This is particularly true for the documentation of specific pain-related issues, work activities and personal factors. To ensure the practicability of the multidisciplinary evaluation process, the large number of ICF categories and context-specific additions necessary for comprehensive documentation could be specifically allocated to the disciplines in charge of their assessment.

Keywords: International Classification of Functioning, Disability and Health (ICF), Medical evaluation of work capacity, Disability evaluation, Chronic widespread pain, Low back pain, Context-specific additions

\footnotetext{
* Correspondence: urban.schwegler@paraplegie.ch

${ }^{1}$ Swiss Paraplegic Research (SPF), Nottwil, Switzerland

${ }^{2}$ Department of Health Sciences and Health Policy, University of Lucerne and

SPF, Nottwil, Switzerland

Full list of author information is available at the end of the article
} 


\section{Background}

Medical evaluations of work capacity (MEWC) determine a claimant's diagnoses and work capacity as the key information for decisions on eligibility for benefits provided by national disability insurances. To ensure a fair eligibility decision process, MEWC should be documented as transparently and comprehensibly as possible [1]. Moreover, MEWC should also be comparable in terms of interrater reliability between the medical experts who are in charge of the assessments [2,3].

In reality, however, MEWC are often reported in a poorly standardized way [2] and charged with low interrater reliability [4]. Furthermore, in many European countries the determination of a health condition is required as a key criterion for disability benefits eligibility [5, Annex] although health conditions taken by themselves are usually only loosely correlated with work ability limitations [6]. In contrast, modern medical thinking defines disability not simply as the consequence of a health condition but as the result of various biopsychosocial interactions [7]. Hence, transparent MEWC require comprehensive reporting of functional limitations and their determinants, not only in terms of impairments or health conditions but also in terms of contextual factors.

The International Classification of Functioning, Disability and Health (ICF) [7] provides a comprehensive biopsychosocial framework that conceptualizes functioning as the interplay between a health condition, body functions and body structures, activities and participation as well as contextual factors, i.e. environmental and personal factors (see Figure 1). The ICF framework thus appears promising for ensuring transparent reporting in MEWC. The ICF taxonomy is considered the worldwide standard for reporting on functioning and disability and offers a comprehensive spectrum of categories for documenting all components of the framework except personal factors which are not classified. In addressing 362 categories on the second level (e.g. b280 Sensation of pain) and up to 1,424 categories on the more specific third or fourth levels (e.g. b2801 Pain in body part and b28013 Pain in back), the ICF taxonomy provides a common language for standardizing MEWC and enhancing their interrater reliability [8].

Applying the ICF could be particularly beneficial in MEWC of claimants with chronic pain which are in Switzerland often conducted in multidisciplinary settings. The impact of pain on functioning, and thus on work ability, depends on complex biopsychosocial interactions [9]. Therefore, a comprehensive and accurate documentation of functional limitations and their determinants is needed for transparent MEWC involving chronic pain.

So far, no empirical studies have examined the comprehensiveness of the ICF taxonomy in covering the core content of MEWC. Conceptual papers on the applicability of the ICF in MEWC argue that the ICF is neither useful for describing (in)consistencies and causal relationships between impairments, contextual influences, activity limitations and work ability restrictions, nor for addressing the dynamic development of disability over time $[10,11]$. However, since these issues reflect procedural and decisional challenges in MEWC rather than specific aspects related to functioning, they fall beyond the scope of the ICF taxonomy and will not be further dwelled upon in this study.

Yet, the comprehensiveness of the ICF taxonomy in addressing core aspects of specific contexts of application has been empirically studied in fields other than MEWC, including work and pain assessments. A need for context-specific additions to the ICF was identified with regard to the following four areas.

(1) Precision refers to the number of distinct levels of specification within an ICF category [12]. Some categories may not be specific enough for contexts requiring highly

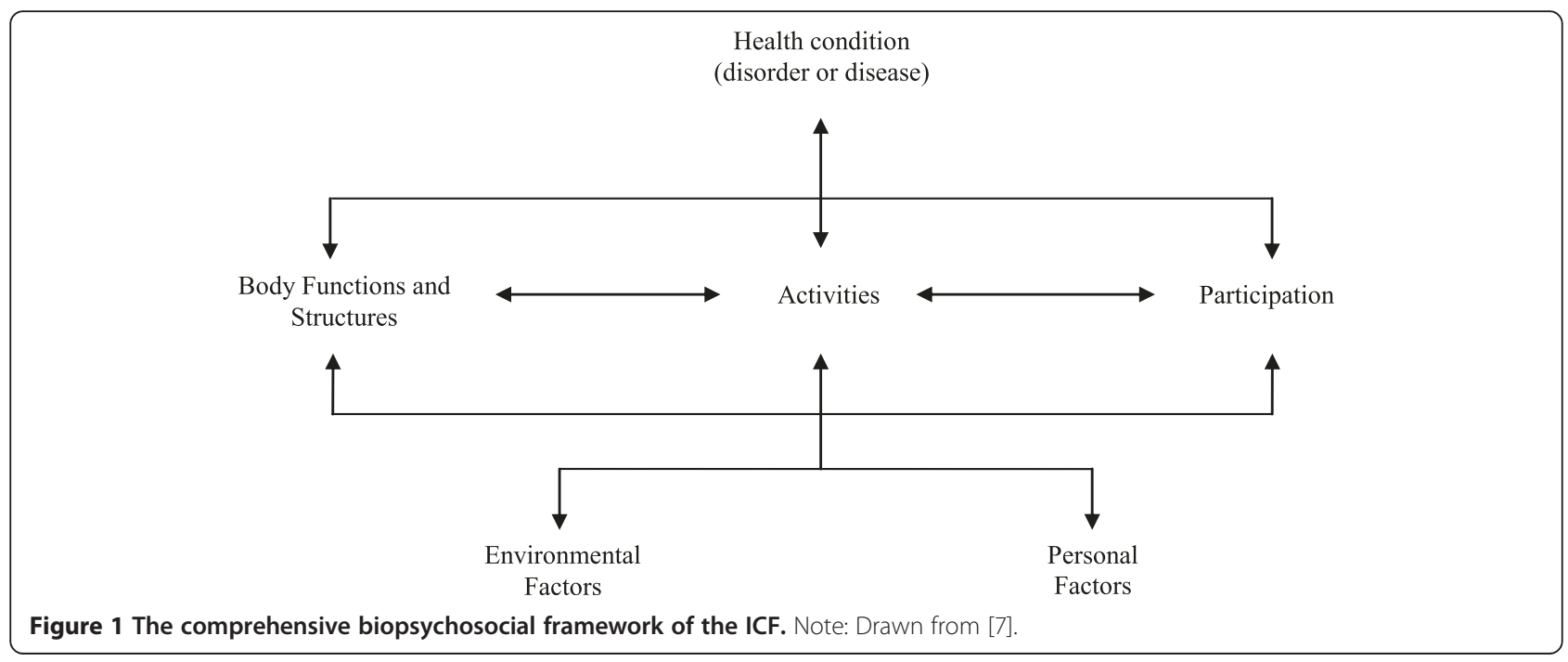


accurate reporting of health-related aspects [13]. Existing ICF categories do not allow for describing the pain location or features of pain quality such as pressure, stabbing or rest pain at a sufficient level of detail [14,15]. Additionally, specific work activities such as "overhead working" or "forward bending stand" cannot be adequately reported with ICF categories [16]. Therefore, when applying the ICF taxonomy for accurate reporting in a specific context, category specifications may be developed for exclusive use in this particular context.

To exploit the maximum precision of the ICF categories for documentation in specific contexts, scholars have advocated using the more accurate third or fourth category levels. For pain assessments, this was mainly motivated by the need to differentiate between specific pain locations [15]. In the work context, the third and fourth category levels allow for distinguishing specific work activities such as sitting or standing [17].

(2) Coverage reflects the ability of the ICF taxonomy to comprehensively capture the spectrum of functioning aspects and environmental factors and has formerly been described with the terms exhaustiveness or width [12]. Some work-related aspects such as "overloading" or "overstressing" can, for instance, not be addressed with ICF categories [18]. To address this issue, items that allow for reporting important context-specific aspects not covered by the ICF could be exclusively generated for a particular context.

(3) Personal factors are currently not classified by the ICF taxonomy, although several studies pointed out the need for standardized personal factor categories [19-21]. Psychological aspects that are relevant in the field of chronic pain such as coping strategies, fear-avoidance beliefs or catastrophizing cannot be reported with ICF categories [22,23]. In the contexts of work and MEWC, it would be important to have categories for the documentation of personal factors such as a claimant's occupational background, work motivation or expectations regarding return to work $[24,25]$.

(4) Broad concepts such as quality of life or general health were also mentioned as not being classified by the ICF [26]. However, as the ICF taxonomy aims at categorizing specific aspects related to functioning and health rather than overall concepts, this issue appears to be less pertinent.

Applying the ICF taxonomy to code the content of medical reports is one possible way to empirically test its comprehensiveness in the context of MEWC, and to establish aspects that are not addressable with ICF categories at all or not in a sufficiently specific manner. This is, however, based on the assumption that current medical reports do indeed include the crucial aspects of MEWC. In a recent study [27], we found that the ICF Core Sets for chronic widespread pain (CWP) [23], low back pain (LBP) [28] and two major co-morbidities, i.e. depression [29] and obesity [30], cover the relevant aspects of functioning and environmental factors in reports on Swiss disability claimants with CWP and LBP to a fair extent. However, the study only focused on second level ICF categories. Moreover, a number of concepts in the reports were not appropriately classifiable with the ICF. A more in-depth analysis of these concepts is necessary to properly establish aspects to be added when applying the ICF taxonomy for comprehensive reporting in MEWC.

The present study aims at providing additions to the ICF exclusively for its application in MEWC involving chronic pain and not for an update of the ICF taxonomy in general. Therefore, a context-specific addition (or a specification category) refers to a complement to the ICF taxonomy for this particular field of application. The four abovementioned specification areas (i.e. precision, coverage, personal factors, broad concepts) will serve as a structuring device for presenting the study results.

\section{Objective}

The objective of this study was to identify potential contextspecific additions to the ICF taxonomy for its application in MEWC involving CWP and LBP.

\section{Specific aims}

The specific aims were (1) to identify and specify content of medical reports on claimants with CWP and/or LBP not appropriately classifiable with the ICF; and (2) to determine specification categories as well as third and fourth level ICF categories that appear relevant across these reports.

\section{Methods}

\section{Study design}

We conducted a retrospective qualitative and quantitative content analysis of 72 medical reports [31]. In the qualitative part the reports were coded using the ICF, while in the quantitative part a frequency analysis of the coded categories was carried out.

\section{Ethics}

The study was approved by the Ethics Commission of Basel, Switzerland, project number 134/08, and performed in accordance to the Declaration of Helsinki.

\section{Sample}

The available sample included all 209 reports in German that were submitted to the Swiss national disability insurance scheme between February $1^{\text {st }}$ and April $30^{\text {th }} 2008$, and contained a diagnosis of CWP and/or LBP. We used a selection of International Classification of Diseases (ICD10) codes as inclusion criteria (see Table 1). The reports were selected and anonymized by insurance employees and could include one, two or more medical disciplines. 
Table 1 ICD-10 diagnoses included in the sample

\begin{tabular}{ll}
\hline ICD-10 diagnoses for CWP & ICD-10 diagnoses for LBP \\
\hline F45.0 Somatization disorder & M42 Spinal osteochondrosis \\
& $(.15-.17, .95-.97)$ \\
F45.1 Undifferentiated somatoform & M45 Ankylosing spondylitis \\
disorder & \\
F45.4 Persistent somatoform & M46 Other inflammatory \\
disorder & spondylopathies $(.0, .1, .2, .3)$ \\
F54 Psychological and behavioral & M47 Spondylosis and \\
factors associated with disorders or & $($ osteo-)arthrosis of spine \\
diseases classified elsewhere & $(.05-.07, .15-.17, .25-.27)$ \\
F62.8 Chronic pain personality syndrome & M48 Other spondylopathies \\
& $(.05-.07, .15-.17, .25-.27)$ \\
F32 Mild, moderate and severe depressive & M51 Other intervertebral \\
episode, with somatic symptoms & disc disorders $(.0, .1)$ \\
F33 Recurrent depressive disorder, & M53 Other dorsopathies, \\
with somatic symptoms & not elsewhere classified \\
& $(.25-.27, .3, .86-.87, .96-.97)$ \\
F34.1 Dysthymia (in relation with pain) & M54 Dorsalgias $(.05-.07$, \\
& $.15-.17, .3, .4, .5, .85-.87)$ \\
F43.2 Adjustment disorders & M99 Biomechanical lesions, \\
M79.7 Fibromyalgia & not elsewhere classified \\
R52.2 Other chronic pain & $(.03, .13, .23, .33, .43, .53$, \\
\hline & $.63, .73, .83, .93)$ \\
& \\
\hline
\end{tabular}

Note: Drawn from [27].

From this available sample we drew a subsample whose final size was determined based on two criteria: (1) saturation, i.e. the assumption that the collected information is sufficient when no new second level ICF category appears in five successive reports analyzed [32,33]; and (2) heterogeneity, i.e. the proportional inclusion of both the relevant medical disciplines of pain assessment (e.g. rheumatology, psychiatry or neurology) and the index conditions (i.e. CWP, LBP) involved in the reports. The heterogeneity criterion was applied to capture the diversity of the concepts relevant in the present context. Taking into account the two abovementioned heterogeneity dimensions a minimum subsample size of 72 reports, representing about one third of the available sample of 209 reports, was determined. The reports were randomly drawn from the available sample and the order in which they were analyzed was randomly determined.

\section{Analysis}

We subdivided the sample into reports with CWP and with LBP diagnoses. Reports including both diagnoses were analyzed twice, once with the pure CWP and once with the pure LBP reports.

\section{Content analysis}

In Switzerland, MEWC are usually documented in free text by medical experts. Reports consist of three main sections that comprehensively address the claimant's situation. (1) The socio-medical history describes the claimant's occupational, biographical and medical background and his or her functioning in everyday life, including subjective claims regarding impairments and functional limitations. (2) The medical examination aims at an objective assessment of functional capacity and documents the expert's findings regarding the claimant's physical or mental impairments leading to the final diagnoses. (3) The work capacity evaluation provides a synthesis of the two previous sections and an appraisal of the claimant's work capacity based on his or her functional capacity and diagnoses. In addition, the consistency between subjective claims and objective findings is discussed. Finally, a longterm prognosis is provided and measures to improve the claimant's work capacity are suggested.

We coded the content of the reports using the ICF and established linking rules $[34,35]$. Pre-existing medical records on the claimant were not analyzed. First, we divided the reports into units of meaning referring to passages with a common theme (e.g. "the claimant suffers from pain while sitting"). Then, we determined the different concepts underlying a unit of meaning (e.g. pain, sitting) and coded them to the most precise ICF category (e.g. b280 Sensation of pain, d4153 Maintaining a sitting position). To ensure data quality, all reports were coded by two health professionals familiar with the ICF and trained in the linking method. In case of discrepancies, the coders discussed and agreed on their final coding. Any disagreement was resolved by consulting a third subject-matter specialist. Interrater reliability between the two coders was determined based on percentage agreement [36].

The coders also assessed whether concepts reflected limitations or barriers for the claimant (e.g. "the cold weather worsens the claimant's health"), were facilitators (e.g. "the warm weather supports the claimant's recovery"), no problem (e.g. "the weather does not influence the claimant's health"), or facts (e.g. "the weather is usually mild where the claimant lives").

Concepts not appropriately classifiable with the ICF were labeled with a specification code as either personal factors, not covered, not definable (broad concepts) or health condition. The codes other specified, not definable (within ICF components) or combination category were applied when concepts could not be addressed sufficiently precisely within ICF categories. Table 2 provides examples and definitions for the different types of specification categories.

We assigned the categories to the four specification areas precision, coverage, personal factors and broad concepts (see Table 2). Information referring to causal relationships, consistency or time-related aspects was not considered for the content analysis. 
Table 2 Specification areas, type of specification categories, examples for specification codes and definitions for the different types of specification categories referring to concepts in the medical reports not appropriately codeable with the ICF

\begin{tabular}{|c|c|c|}
\hline Specification area & $\begin{array}{l}\text { Type of specification categories and } \\
\text { examples for specification codes }\end{array}$ & Definition of specification category \\
\hline \multirow[t]{6}{*}{ (1) Precision } & Combination category & Location of a body function \\
\hline & e.g. b7101(s7201) & e.g. mobility of shoulder joint \\
\hline & Not definable (within ICF components) & Concepts which can be coded to more than one ICF category within a component \\
\hline & e.g. nd-d(ohw) & e.g. overhead working \\
\hline & Other specified & Concepts not differentiable within an ICF category \\
\hline & e.g. d4158 & e.g. maintaining a bending position \\
\hline \multirow[t]{6}{*}{ (2) Coverage } & Not covered & Not covered by the ICF \\
\hline & e.g. nc-acc & e.g. accidents \\
\hline & Not covered - work (in)capacity & Not covered within the ICF (general work (in)capacity) \\
\hline & e.g. nc-WC; nc-WIC & e.g. work (in)capacity \\
\hline & Health condition & Health conditions \\
\hline & e.g. hc & e.g. depression \\
\hline \multirow[t]{2}{*}{ (3) Personal factors } & Personal factors & Personal factors \\
\hline & e.g. pf-edu & e.g. educational background \\
\hline \multirow[t]{2}{*}{ (4) Broad concepts } & Not definable (broad concepts) & Not definable broad concepts \\
\hline & e.g. nd-gh & e.g. general health \\
\hline
\end{tabular}

\section{Relevance analysis}

The relevance analysis only included specification categories and third or fourth level ICF categories assessed as limitations, barriers or facilitators and thus assumed to influence the claimant's functioning. We removed second level ICF categories identified in our previous study [27] from the analysis. In addition, we excluded concepts from the specification area coverage referring to health condition or to the legal term work (in)capacity and broad concepts. The former because a health condition such as depression can be classified using an ICD-10 code. The latter two since classifying overall concepts would not match the ICF's basic tenet and is not further increasing a comprehensive and accurate reporting of functioning aspects and their determinants in MEWC.

We operationalized the relevance of a category as its relative frequency across reports, i.e. the percentage of reports it was addressed in at least once, and applied a relevance threshold at 25\%. All categories above this threshold were considered relevant context-specific additions to the ICF for MEWC involving CWP and LBP. The selection of a particular threshold always involves an arbitrary element. For the purpose of this study, we first analyzed the frequency and diversity of the categories with regard to three different thresholds, i.e. $75 \%$, $50 \%$ and $25 \%$. We eventually settled on the most lenient threshold at $25 \%$ so as to arrive at a comprehensive picture of the relevant context-specific additions across reports.
Figure 2 illustrates the content selection process applied in our study.

\section{Results}

\section{Sample characteristics}

The saturation criterion was reached after coding 30 medical reports. However, to fulfill the heterogeneity requirement, we set the minimum size of the subsample to be 72 reports, representing about one third of the available sample of 209 reports. We considered this sample size big enough to ensure a proportional inclusion of the index conditions and the medical disciplines involved in the reports. 27 of the reports contained only a CWP diagnosis, 22 only a LBP diagnosis, and 23 both a CWP and LBP diagnosis. In the CWP group 20 reports included one, 4 two and 26 more than two medical disciplines, while in the LBP group 14 reports consisted of one, 5 of two and 26 of more than two disciplines. In both group of reports, psychiatry and rheumatology were the most frequent medical disciplines.

\section{Interrater reliability}

The percentage agreement between the two coders was $78.7 \%$ for the ICF categories and $78.8 \%$ for the specification categories in the reports.

\section{Reports with CWP diagnoses Content analysis}

A total of 21,562 units of meaning led to 45,365 (100\%) codings. Out of these, 24,396 (53.7\%) represented pure 


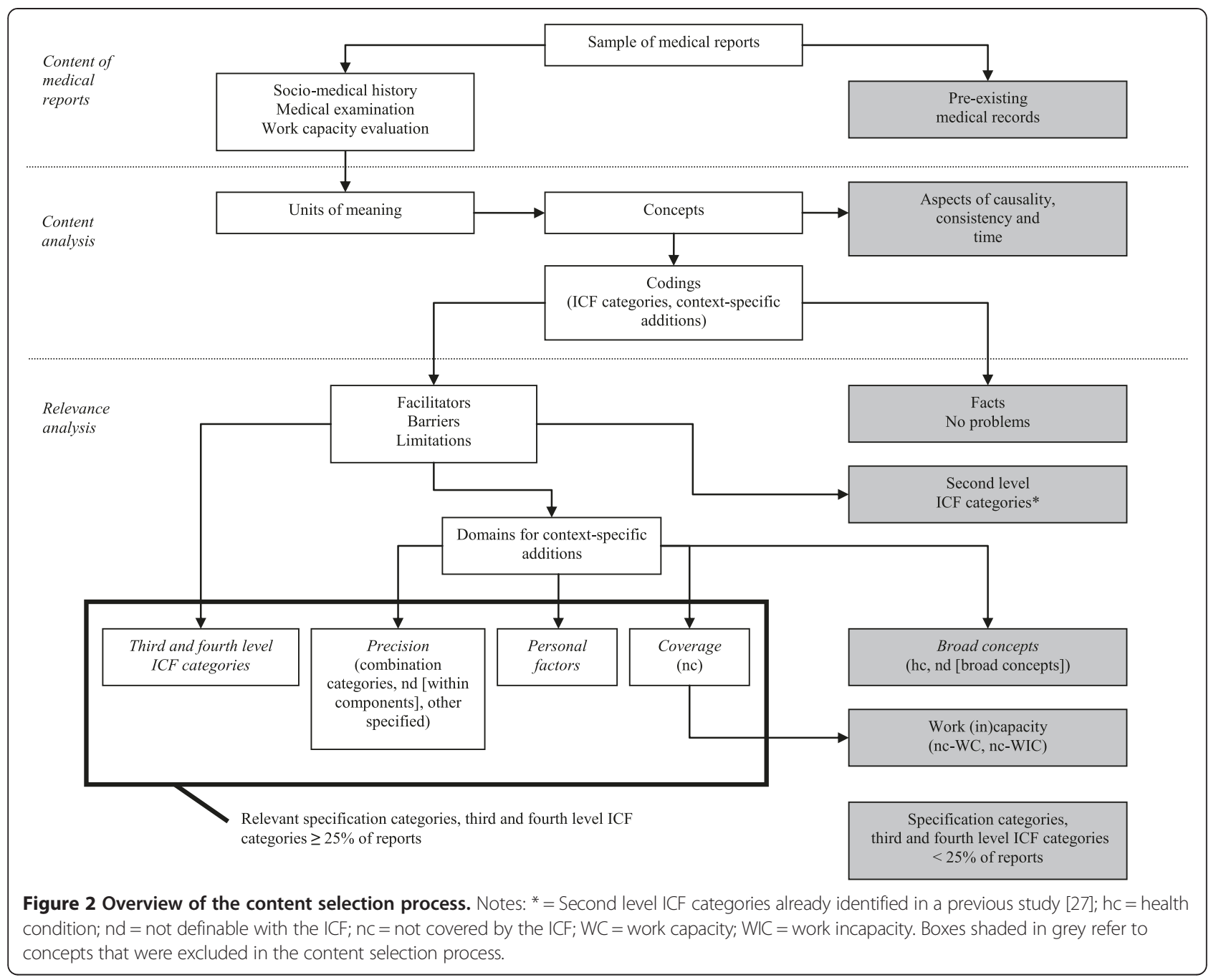

ICF categories. The rest $(20,969$ or $46.3 \%)$ was not classifiable appropriately or precisely enough with the ICF. Table 3 displays the codings' frequencies for the different types of specification categories and specification areas.

Of the $24,396(100 \%)$ codings referring to ICF categories, $8,413(34.5 \%)$ were coded on the second, 13,810 $(56.6 \%)$ on the third and $2,173(8.9 \%)$ on the fourth level.

\section{Relevant specification categories}

Overall, 5,146 codings for specification categories and 5,482 for third and fourth level ICF categories were assessed as limitations, barriers or facilitators and thus included in the relevance analysis. 454 different specification categories were identified. Forty-three of them passed the 25\%-threshold and were considered relevant for medical reports on claimants with CWP. Thirty-one categories belonged to the area precision, 10 to personal factors and 2 to coverage (see Table 4). In addition, 70
Table 3 Absolute and relative frequency of the codings for the different types of specification categories and specification areas in relation to the total number of codings ( $k=45,365)$ in the CWP reports $(n=50)$

\begin{tabular}{|c|c|c|c|}
\hline Specification area & $\begin{array}{l}\text { Type of specification } \\
\text { categories }\end{array}$ & $\begin{array}{l}\text { Absolute } \\
\text { frequency }\end{array}$ & $\begin{array}{l}\text { Relative } \\
\text { frequency \% }\end{array}$ \\
\hline \multirow[t]{4}{*}{ (1) Precision } & Combination categories & 4,775 & 10.5 \\
\hline & $\begin{array}{l}\text { Not definable (within } \\
\text { components) }\end{array}$ & 592 & 1.3 \\
\hline & Other specified & 871 & 1.9 \\
\hline & & 6,238 & 13.8 \\
\hline \multirow[t]{4}{*}{ (2) Coverage } & Not covered & 3,324 & 7.3 \\
\hline & $\begin{array}{l}\text { Not covered - work } \\
\text { (in)capacity }\end{array}$ & 770 & 1.7 \\
\hline & Health condition & 2,243 & 4.9 \\
\hline & & 6,337 & 13.9 \\
\hline (3) Personal factors & Personal factors & 4,276 & 9.4 \\
\hline (4) Broad concepts & $\begin{array}{l}\text { Not definable } \\
\text { (broad concepts) }\end{array}$ & 4,118 & 9.1 \\
\hline
\end{tabular}


Table 4 Relative frequency of the specification categories (subdivided in specification areas) in the CWP reports ( $n=50$ )

\begin{tabular}{|c|c|c|c|}
\hline $\begin{array}{l}\text { Specification } \\
\text { area }\end{array}$ & Code & Specification category & $\begin{array}{l}\text { Relative } \\
\text { frequency \% }\end{array}$ \\
\hline \multirow[t]{31}{*}{ (1) Precision } & nd-d(hph-l) & Heavy physical labor & 60 \\
\hline & b28016(s76002) & Pain in joints (Lumbar vertebral column) & 56 \\
\hline & b7101(s76002) & Mobility of several joints (Lumbar vertebral column) & 56 \\
\hline & b2801(s7601) & Pain in body part (Muscles of trunk) & 54 \\
\hline & b2801(s740) & Pain in body part (Structure of pelvic region) & 48 \\
\hline & b2801(s720) & Pain in body part (Structure of shoulder region) & 46 \\
\hline & b28016(s76000) & Pain in joints (Cervical vertebral column) & 46 \\
\hline & b7101(s76000) & Mobility of several joints (Cervical vertebral column) & 46 \\
\hline & b2801(s710) & Pain in body part (Structure of head and neck region) & 44 \\
\hline & b28015(s7500) & Pain in lower limb (Structure of thigh) & 44 \\
\hline & b1268 & Temperament and personality functions, other specified (Aggravation, simulation) & 44 \\
\hline & b2702(s730) & Sensitivity to pressure (Structure of upper extremity) & 42 \\
\hline & b28016(s75011) & Pain in joints (Knee joint) & 42 \\
\hline & b2803(s750) & Radiating pain in a dermatome (Structure of lower extremity) & 42 \\
\hline & b7350(s75002) & Tone of isolated muscles and muscle groups (Muscles of thigh) & 42 \\
\hline & b2702(s750) & Sensitivity to pressure (Structure of lower extremity) & 38 \\
\hline & b28016(s7201) & Pain in joints (Joints of shoulder region) & 38 \\
\hline & $\mathrm{d} 2408$ & $\begin{array}{l}\text { Handling stress and other psychological demands, other specified } \\
\text { (Behavior during medical examination) }\end{array}$ & 38 \\
\hline & s76082 & Structure of trunk, other specified (Lumbar intervertebral disk) & 38 \\
\hline & b7350(s7601) & Tone of isolated muscles and muscle groups (Muscles of trunk) & 36 \\
\hline & nd-d(ohw) & Overhead working & 34 \\
\hline & $n d-d(f p)$ & Forced postures & 34 \\
\hline & b28015(s7501) & Pain in lower limb (Structure of lower leg) & 32 \\
\hline & b28014(s7302) & Pain in upper limb (Structure of hand) & 30 \\
\hline & b28016(s76001) & Pain in joints (Thoracic vertebral column) & 30 \\
\hline & b2803(s7500) & Radiating pain in a dermatome (Structure of thigh) & 30 \\
\hline & b7101(s75001) & Mobility of several joints (Hip joint) & 28 \\
\hline & b7101(s7401) & Mobility of several joints (Joints of pelvic region) & 26 \\
\hline & b7101(s76001) & Mobility of several joints (Thoracic vertebral column) & 26 \\
\hline & nd-d(rep) & Repetitive work activities & 26 \\
\hline & e1108 & $\begin{array}{l}\text { Products or substances for personal consumption, other specified } \\
\text { (Stimulants like alcohol or nicotine) }\end{array}$ & 26 \\
\hline \multirow[t]{2}{*}{ (2) Coverage } & nc-fam & Genetic aspects & 70 \\
\hline & nc-acc & Accidents & 58 \\
\hline \multirow{10}{*}{$\begin{array}{l}\text { (3) Personal } \\
\text { factors }\end{array}$} & pf-othchar & Other personal characteristics (e.g. personal expectations, beliefs and attitudes) & 90 \\
\hline & pf-exp & Past and current experience (past life events and concurrent events) & 88 \\
\hline & pf-edu & Education & 84 \\
\hline & pf-fam & Family and marital status & 84 \\
\hline & pf-psychassets & Individual psychological assets & 76 \\
\hline & pf-copstyles & Coping styles & 70 \\
\hline & pf-lifestyle & Lifestyle & 62 \\
\hline & pf-socbac & Social background & 58 \\
\hline & pf-char & Overall behavior pattern and character style & 52 \\
\hline & pf-prof & Profession & 52 \\
\hline
\end{tabular}


Table 5 Relative frequency of the third and fourth level ICF categories in the CWP reports $(n=50)$

\begin{tabular}{|c|c|c|c|c|c|}
\hline $\begin{array}{l}\text { ICF } \\
\text { code }\end{array}$ & Third or fourth level ICF category & $\begin{array}{l}\text { Relative } \\
\text { frequency \% }\end{array}$ & b1520 & Appropriateness of emotion & 38 \\
\hline $\mathrm{e} 5800$ & Health services & 88 & $d 7601$ & Child-parent relationships & 38 \\
\hline b28013 & Pain in back & 86 & d7602 & Sibling relationships & 38 \\
\hline b28016 & Pain in joints & 84 & b7301 & Power of muscles of one limb & 36 \\
\hline e1101 & Drugs & 82 & d8501 & Part-time employment & 36 \\
\hline b1265 & Optimism & 78 & b28012 & Pain in stomach or abdomen & 36 \\
\hline b28015 & Pain in lower limb & 76 & b4200 & Increased blood pressure & 36 \\
\hline b28010 & Pain in head and neck & 76 & $d 4501$ & Walking long distances & 36 \\
\hline b1602 & Content of thought & 74 & b7300 & Power of isolated muscles and muscle groups & 34 \\
\hline b7101 & Mobility of several joints & 74 & b1522 & Range of emotion & 34 \\
\hline b2702 & Sensitivity to pressure & 70 & b7305 & Power of muscles of the trunk & 34 \\
\hline b2803 & Radiating pain in a dermatome & 70 & $d 2401$ & Handling stress & 34 \\
\hline s7600 & Structure of vertebral column & 70 & $d 7600$ & Parent-child relationships & 34 \\
\hline d5702 & Maintaining one's health & 70 & s76003 & Sacral vertebral column & 34 \\
\hline b1342 & Maintenance of sleep & 68 & s7501 & Structure of lower leg & 32 \\
\hline e1650 & Financial assets & 68 & e2450 & Day/night cycles & 32 \\
\hline d8700 & Personal economic resources & 64 & s76000 & Cervical vertebral column & 32 \\
\hline b1301 & Motivation & 60 & b1263 & Psychic stability & 30 \\
\hline b1603 & Control of thought & 60 & b1341 & Onset of sleep & 30 \\
\hline$d 4153$ & Maintaining a sitting position & 60 & b7355 & Tone of muscles of trunk & 30 \\
\hline b28014 & Pain in upper limb & 58 & d4104 & Standing & 30 \\
\hline b7350 & Tone of isolated muscles and muscle groups & 58 & $d 4751$ & Driving & 30 \\
\hline s76002 & Lumbar vertebral column & 58 & $\mathrm{e} 2250$ & Temperature & 30 \\
\hline b2802 & Pain in multiple body parts & 56 & b1260 & Extraversion & 26 \\
\hline b4552 & Fatiguability & 56 & b1266 & Confidence & 26 \\
\hline b1521 & Regulation of emotion & 54 & $d 5701$ & Managing diet and fitness & 26 \\
\hline b1303 & Craving & 52 & $\mathrm{~d} 7202$ & Regulating behaviors within interactions & 26 \\
\hline
\end{tabular}

s7502 Structure of ankle and foot 48

b1261 Agreeableness 48

d4300 Lifting 48

e5702 Social security policies $\quad 48$

b1302 Appetite 46

d4150 Maintaining a lying position 46

d7701 Spousal relationships 46

s76001 Thoracic vertebral column 46

d8450 Seeking employment 44

d2402 Handling crisis 44

e5700 Social security services 44

d2303 Managing one's own activity level 42

b2703 Sensitivity to noxious stimulus 40

b2800 Generalized pain 40

b1470 Psychomotor functions $\quad 40$

d4154 Maintaining a standing position 40

d8502 Full-time employment 38
Table 5 Relative frequency of the third and fourth level ICF categories in the CWP reports $(n=50)$ (Continued)

third or fourth level ICF categories passed the relevance threshold (see Table 5).

\section{Reports with LBP diagnoses Content analysis}

A total of 21,707 units of meaning resulted in 42,116 (100\%) codings. Out of these, 22,333 (53\%) represented pure ICF categories. The remainder $(19,783$ or $47 \%)$ was not classifiable appropriately or precisely enough with the ICF. Table 6 presents the codings' frequencies for the different types of specification categories and specification areas.

Of the 22,333 (100\%) codings referring to ICF categories, $6,712(30.1 \%)$ were coded on the second, 12,588 (56.4\%) on the third and 3,033 (13.6\%) on the fourth level.

\section{Relevant specification categories}

Overall, 4,860 codings for specification categories and 5,184 for third and fourth level ICF categories were 


\begin{tabular}{|c|c|c|c|}
\hline Specification area & $\begin{array}{l}\text { Type of specification } \\
\text { categories }\end{array}$ & $\begin{array}{l}\text { Absolute } \\
\text { frequency }\end{array}$ & $\begin{array}{l}\text { Relative } \\
\text { frequency } \%\end{array}$ \\
\hline \multirow[t]{4}{*}{ (1) Precision } & Combination categories & 5,297 & 12,6 \\
\hline & $\begin{array}{l}\text { Not definable } \\
\text { (within components) }\end{array}$ & 623 & 1.5 \\
\hline & Other specified & 1,246 & 3.0 \\
\hline & & 7,166 & 17.0 \\
\hline \multirow[t]{4}{*}{ (2) Coverage } & Not covered & 2,568 & 6.1 \\
\hline & $\begin{array}{l}\text { Not covered - work } \\
\text { (in) capacity }\end{array}$ & 754 & 1.8 \\
\hline & Health condition & 2,571 & 6.1 \\
\hline & & 5,893 & 14.0 \\
\hline (3) Personal factors & Personal factors & 3,111 & 7.4 \\
\hline (4) Broad concepts & $\begin{array}{l}\text { Not definable } \\
\text { (broad concepts) }\end{array}$ & 3,613 & 8.6 \\
\hline
\end{tabular}

assessed as limitations, barriers or facilitators and thus included in the relevance analysis. 438 different specification categories were identified. Fifty-two of them passed the 25\%-threshold and were considered relevant for medical reports on claimants with LBP. Forty categories belonged to the area precision, 10 to personal factors and 2 to coverage (see Table 7). In addition, 67 third or fourth level ICF categories passed the relevance threshold (see Table 8).

\section{Discussion}

We identified several potential context-specific additions to the ICF taxonomy for its application in MEWC involving CWP and LBP. Moreover, we found a substantial number of third and fourth level ICF categories to be relevant for this particular context. The specification categories were assigned to the four specification areas precision, coverage, personal factors and broad concepts. For reasons given in the methods section, the categories referring to broad concepts were not considered relevant context-specific additions for the use of the ICF in MEWC.

Precision was in both groups of reports the most common specification area and reflects category specifications that need to be considered when applying the ICF for comprehensive reporting in MEWC involving CWP and LBP. For instance, the ICF category for joint pain (i.e. b28016 Pain in joints) lacks granularity in MEWC as it does not distinguish between different locations of joint pain. Such a differentiation, however, is important in MEWC as joint pain may affect different work activities depending on its location. While pain in the lumbar vertebral column, for example, may limit bending, shoulder pain interferes with activities requiring hand and arm use. Category specifications for different locations of joint pain could facilitate an accurate reporting of such relations when using the ICF in MEWC. In addition, important work activities such as overhead working involve aspects covered by several different ICF categories and cannot be adequately reported with one single ICF category. This problem could be resolved by introducing context-specific additions to the ICF addressing the work activities concerned.

The large number of third or fourth level ICF categories above the relevance threshold indicates their importance when applying the ICF in MEWC involving chronic pain. This is particularly true for describing pain locations on the one hand and work activities on the other, and is consistent with findings of studies in the contexts of work and pain assessments $[15,16]$.

As to a potential lack of specificity of ICF categories, it needs to be emphasized that the ICF taxonomy aims at providing a universally applicable standard for reporting health and functioning information rather than at offering accurate categories for reporting specific aspects of particular disciplines, contexts or health conditions. In this respect, our findings regarding a lack of specificity of some ICF categories are not surprising, but with regard to the potential applicability of the ICF in the present context nevertheless noteworthy. Alternative to the use of context-specific additions it is also possible to report aspects that cannot be accurately classified with ICF categories by using free text and without applying specific ICF-related codes.

Personal factors are the second important area for context-specific additions to the ICF in MEWC involving CWP and LBP. Standardized reporting of psychological aspects such as coping strategies or pain beliefs [23] as well as occupational experiences or work motivation [24] is crucial for pain and work ability assessments. In MEWC, personal factor categories may be helpful in illustrating whether functional limitations are likely due to a health condition (e.g. "depressive symptoms") or due to individual characteristics (e.g. "reduced work motivation"). Whilst in the former case claimants may be entitled to receive a disability pension, in the latter they are more likely to be assigned to a return to work program. Most relevant personal factors in the context of MEWC involving chronic pain were found to be the claimant's educational, occupational and biographical background, behavior patterns as well as personal emotions and cognitions such as, for instance, expectations related to the job [25]. As an alternative to the determination of context-specific additions for personal factors, already existing personal factor taxonomies 
Table 7 Relative frequency of the specification categories (subdivided in specification areas) in the LBP reports ( $\mathrm{n}=45$ )

\begin{tabular}{|c|c|c|}
\hline Specification area & Code & Specification category \\
\hline \multirow[t]{40}{*}{ (1) Precision } & b7101(s76002) & Mobility of several joints (Lumbar vertebral column) \\
\hline & b28016(s76002) & Pain in joints (Lumbar vertebral column) \\
\hline & s76082 & Structure of trunk, other specified (lumbar intervertebral disks) \\
\hline & b7101(s76002) & Mobility of several joints (Lumbar vertebral column) \\
\hline & b2803(s750) & Radiating pain in a dermatome (Structure of lower extremity) \\
\hline & nd-d(hph-l) & Heavy physical labor \\
\hline & b7350(s75002) & Tone of isolated muscles and muscle groups (Muscles of thigh) \\
\hline & b2801(s7601) & Pain in body part (Muscles of trunk) \\
\hline & b28016(s7201) & Pain in joints (Joints of shoulder region) \\
\hline & b7350(s7601) & Tone of isolated muscles and muscle groups (Muscles of trunk) \\
\hline & b2803(s7500) & Radiating pain in a dermatome (Structure of thigh) \\
\hline & s76083 & Structure of trunk, other specified (sacral intervertebral disks) \\
\hline & b7101(s7401) & Mobility of several joints (Joints of pelvic region) \\
\hline & nd-d(fp) & Forced postures \\
\hline & b7101(s76001) & Mobility of several joints (Thoracic vertebral column) \\
\hline & nd-d(ohw) & Overhead working \\
\hline & b7101(s75001) & Mobility of several joints (Hip joint) \\
\hline & b7101(s7600) & Mobility of several joints (Structure of vertebral column) \\
\hline & b1268 & Temperament and personality functions, other specified (Aggravation, simulation) \\
\hline & $\mathrm{d} 2408$ & $\begin{array}{l}\text { Handling stress and other psychological demands, other specified } \\
\text { (Behavior during examination) }\end{array}$ \\
\hline & d4158 & Maintaining a body position, other specified (Maintaining a bending position) \\
\hline & b28016(s76001) & Pain in joints (Thoracic vertebral column) \\
\hline & b2803(s710) & Radiating pain in a dermatome (Structure of head and neck region) \\
\hline & b2803(s7502) & Radiating pain in a dermatome (Structure of ankle and foot) \\
\hline & b7108 & Mobility of joint functions, other specified (Single multiple joint) \\
\hline & $\mathrm{d} 4108$ & Changing a basic body position, other specified (Back or head rotations) \\
\hline & b28016(s75011) & Pain in joints (Knee joint) \\
\hline & s76080 & Structure of trunk, other specified (Cervical intervertebral disks) \\
\hline & b2702(s7302) & Sensitivity to pressure (Structure of hand) \\
\hline & b2702(s750) & Sensitivity to pressure (Structure of lower extremity) \\
\hline & b2801(s7104) & Pain in body part (Muscles of head and neck region) \\
\hline & b2801(s720) & Pain in body part (Structure of shoulder region) \\
\hline & b750(s75012) & Motor reflex functions (Muscles of lower leg) \\
\hline & b2702(s730) & Sensitivity to pressure (Structure of upper extremity) \\
\hline & b28014(s7302) & Pain in upper limb (Structure of hand) \\
\hline & b28016(s75001) & Pain in joints (Hip joint) \\
\hline & b2803(s730) & Radiating pain in a dermatome (Structure of upper extremity) \\
\hline & b7301(s750) & Power of muscles of one limb (Structure of lower extremity) \\
\hline & nd-d(rep) & Repetitive work activities \\
\hline & nd-d(altact) & Alternating work activities \\
\hline \multirow[t]{2}{*}{ (2) Coverage } & nc-fam & Genetic aspects \\
\hline & nc-acc & Accidents \\
\hline
\end{tabular}


Table 7 Relative frequency of the specification categories (subdivided in specification areas) in the LBP reports $(n=45)$ (Continued)

\begin{tabular}{llll}
\hline (3) Personal factors & pf-fam & Family and marital status & 73 \\
& pf-exp & Past and current experience (Past life events and concurrent events) & 69 \\
& pf-psychassets & Individual psychological assets & 67 \\
pf-othchar & Other personal characteristics (e.g. personal expectations, beliefs and attitudes) & 62 \\
pf-copstyles & Coping styles & Education & 56 \\
pf-edu & Profession & 56 \\
pf-prof & Lifestyle & 47 \\
pf-lifestyle & Overall behavior pattern and character style & 34 \\
pf-char & Social background & 36 \\
\hline
\end{tabular}

could be used for standardized reporting such as the one of Geyh et al. [37] or Grotkamp et al. [38]. These taxonomies have recently been applied for coding the content of MEWC involving CWP [25].

In both groups of reports only two categories from the area coverage passed the relevance threshold (i.e. genetic aspects and accidents). This is a good sign regarding the comprehensiveness and exhaustiveness of the ICF in covering the content of MEWC involving chronic pain, and an indicator that adding context-specific aspects not covered by the ICF is a less pressing issue.

\section{Study limitations}

Our study has some limitations. First, our sample only includes reports in German from the Swiss national disability insurance. Results are thus not generalizable to other insurance schemes nor to countries with different disability evaluation procedures. To test the generalizability of our findings in other insurance schemes or in other national contexts, further validation studies would be required.

Second, in our study we considered medical reports as the gold standard and benchmark for the comprehensiveness of the ICF in capturing the core content of MEWC. However, it is possible that these reports do not address all aspects that are relevant for MEWC in a sufficiently comprehensive manner. Moreover, it is unknown to what extent the information in these reports addresses the subjective experience of the claimants in an unfiltered, uninterpreted and truly person-centered manner. With the application of a rather lenient relevance threshold at $25 \%$, we increased the probability of capturing a comprehensive picture of the relevant aspects across reports and, thus, alleviated the former of these two limitations. However, additional data sources such as interviews with experts or claimants should be considered to validate our findings.

\section{Practical implications}

The context-specific additions to the ICF and the third or fourth level ICF categories we established as relevant for MEWC involving CWP and LBP complete the set of second level categories suggested in our previous study [27]. Our findings are exclusively geared toward the application of the ICF in MEWC involving CWP or LBP and do not represent suggestions for a general adjustment of the ICF taxonomy or for its use in other contexts. Comprehensive documentation based on the ICF categories and the context-specific additions identified in our studies could ensure transparent MEWC and standardize them in terms of what to measure. However, the ICF does not currently provide a proper operationalization for its categories. Therefore, the issue of how to measure the identified categories should be addressed for the time being by assigning validated measurement tools to the categories.

It is obvious that comprehensive reporting involves a considerable amount of categories, which threatens to undermine the practicability of MEWC. In Switzerland, MEWC of claimants with CWP are usually conducted in multidisciplinary settings. To ensure feasible evaluations, the categories could be grouped and assigned to the particular discipline in charge of their assessment (e.g. b152 Emotional functions should be exclusively assessed by psychiatrists). This limits the amount of categories to be assessed by each medical expert and ensures an overall documentation structure of the multidisciplinary evaluations.

\section{Conclusions}

The ICF taxonomy represents a universally applicable standard for reporting health and functioning information. However, when applying the ICF for comprehensive and transparent reporting in MEWC involving CWP and LBP context-specific additions are needed. This is particularly true for the documentation of specific pain- 
Table 8 Relative frequency of the third and fourth level ICF categories in the LBP reports $(n=45)$

\begin{tabular}{|c|c|c|}
\hline $\begin{array}{l}\text { ICF } \\
\text { code }\end{array}$ & Third or fourth level ICF category & $\begin{array}{l}\text { Relative } \\
\text { frequency \% }\end{array}$ \\
\hline b28013 & Pain in back & 100 \\
\hline b28016 & Pain in joints & 98 \\
\hline b7101 & Mobility of several joints & 98 \\
\hline s7600 & Structure of vertebral column & 98 \\
\hline s76002 & Lumbar vertebral column & 93 \\
\hline b2803 & Radiating pain in a dermatome & 89 \\
\hline d4153 & Maintaining a sitting position & 89 \\
\hline b7350 & Tone of isolated muscles and muscle groups & 82 \\
\hline b28010 & Pain in head and neck & 78 \\
\hline s76001 & Thoracic vertebral column & 78 \\
\hline e1101 & Drugs & 76 \\
\hline b28015 & Pain in lower limb & 76 \\
\hline e5800 & Health services & 76 \\
\hline b2702 & Sensitivity to pressure & 71 \\
\hline d4300 & Lifting & 71 \\
\hline d4154 & Maintaining a standing position & 64 \\
\hline e1650 & Financial assets & 62 \\
\hline d8700 & Personal economic resources & 58 \\
\hline b1342 & Maintenance of sleep & 58 \\
\hline d4150 & Maintaining a lying position & 58 \\
\hline b1265 & Optimism & 56 \\
\hline b4200 & Increased blood pressure & 56 \\
\hline s76000 & Cervical vertebral column & 53 \\
\hline s76003 & Sacral vertebral column & 53 \\
\hline d5702 & Maintaining one's health & 53 \\
\hline e5702 & Social security policies & 53 \\
\hline b28014 & Pain in upper limb & 51 \\
\hline b1602 & Content of thought & 49 \\
\hline b1303 & Craving & 47 \\
\hline s7502 & Structure of ankle and foot & 47 \\
\hline b7301 & Power of muscles of one limb & 47 \\
\hline d8450 & Seeking employment & 47 \\
\hline b1301 & Motivation & 44 \\
\hline d8501 & Part-time employment & 44 \\
\hline d4105 & Bending & 44 \\
\hline s7501 & Structure of lower leg & 42 \\
\hline b4552 & Fatiguability & 42 \\
\hline b2802 & Pain in multiple body parts & 42 \\
\hline b7305 & Power of muscles of the trunk & 42 \\
\hline b1603 & Control of thought & 40 \\
\hline b1521 & Regulation of emotion & 40 \\
\hline d4104 & Standing & 40 \\
\hline$d 4501$ & Walking long distances & 40 \\
\hline
\end{tabular}

Table 8 Relative frequency of the third and fourth level ICF categories in the LBP reports $(n=45)$ (Continued)

\begin{tabular}{lll}
\hline b1261 & Agreeableness & 38 \\
d8502 & Full-time employment & 38 \\
e5700 & Social security services & 38 \\
b1302 & Appetite & 36 \\
e2450 & Day/night cycles & 36 \\
d4551 & Climbing & 33 \\
b1470 & Psychomotor control & 33 \\
b7300 & Power of isolated muscles and muscle groups & 33 \\
b28012 & Pain in stomach or abdomen & 33 \\
b7355 & Tone of muscles of trunk & 3 \\
s1201 & Spinal nerves & 3 \\
d2303 & Managing one's own activity level & 3 \\
b2703 & Sensitivity to a noxious stimulus & 3 \\
d7701 & Spousal relationships & 3 \\
b1341 & Onset of sleep & 3 \\
d7602 & Sibling relationships & 3 \\
d7601 & Child-parent relationships & 27 \\
s75011 & Knee joint & 27 \\
e2250 & Temperature & 27 \\
b7303 & Power of muscles in lower half of the body & 29 \\
b7100 & Mobility of a single joint & Ankle joint and joints of foot and toes \\
s75021 & Handling stress \\
d2401 & Managing diet and fitness \\
d5701 & Handling crisis \\
d2402 & & 27 \\
& & \\
&
\end{tabular}

related issues, work activities and personal factors. To ensure the practicability of the multidisciplinary evaluation process, the large number of ICF categories and context-specific additions necessary for comprehensive documentation could be specifically allocated to the disciplines in charge of their assessment.

\section{Abbreviations}

MEWC: Medical evaluations of work capacity; ICF: International Classification of Functioning, Disability and Health; CWP: Chronic widespread pain; LBP: Low back pain; ICD: International Classification of Diseases.

\section{Competing interests}

The authors declare that they have no competing interests.

\section{Authors' contributions}

US and BT drafted the present paper. US and JA carried out the qualitative and quantitative content analysis of the medical reports. AC significantly contributed to the conception and design of the study. AG was substantially involved in the coordination of the study. MB, WB, JA, AG and $A C$ were involved in the interpretation of the data and made substantial comments on the content of this manuscript. All authors read and approved the final manuscript. The study was funded by Swiss Paraplegic Research (SPF) and the Academy of Swiss Insurance Medicine (asim) without external co-financing. 


\section{Acknowledgments}

We thank Heinrich Gall and Wolfgang Segerer for their support in preparing the database for the linking process, and Katharina Karl for her support in linking the information of the medical reports to the ICF. We thank Christine Boldt for her guidance in the planning, coordination and preparation of the study.

\section{Author details}

${ }^{1}$ Swiss Paraplegic Research (SPF), Nottwil, Switzerland. ${ }^{2}$ Department of Health Sciences and Health Policy, University of Lucerne and SPF, Nottwil,

Switzerland. ${ }^{3}$ asim, Academy of Swiss Insurance Medicine, University Hospital Basel, Basel, Switzerland. ${ }^{4}$ Faculty of Social and Human Sciences, School of Psychology, University of Southampton, Southampton S017 1BJ, UK.

Received: 18 November 2013 Accepted: 20 August 2014 Published: 29 August 2014

\section{References}

1. Meershoek A, Krumeich A, Vos R: Judging without criteria? Sickness certification in Dutch disability schemes. Sociol Health IIIn 2007, 29(4):497-514.

2. Matheson LN, Kane M, Rodbard D: Development of new methods to determine work disability in the United States. J Occup Rehabil 2001 11(3):143-154

3. Innes E, Straker L: Attributes of excellence in work-related assessments. Work 2003, 20(1):63-76

4. Rudbeck M, Fonager K: Agreement between medical expert assessments in social medicine. Scand J Public Health 2011, 39(7):766-772.

5. APPLICA, CESEP, European Centre: Study of compilation of disability statistical data from the administrative registers of the member states. Brussels, Belgium: APPLICA, CESEP and European Centre; 2007.

6. Loeser JD, Sullivan M: Doctors, diagnosis, and disability: a disastrous diversion. Clin Orthop Relat Res 1997, 336(336):61-66.

7. World Health Organization: International Classification of Functioning, Disability and Health (ICF). Geneva: World Health Organization; 2001.

8. Kirschneck M, Winkelmann A, Kirchberger I, Glässel A, Ewert T, Stucki G, Cieza A: Anwendung der ICF Core Sets in der Begutachtung von Patienten mit lumbalen Rückenschmerzen und generalisiertem Schmerzsyndrom. Gesundheitswesen 2008, 70(11):674-678.

9. Laisne F, Lecomte C, Corbiere M: Biopsychosocial determinants of work outcomes of workers with occupational injuries receiving compensation: a prospective study. Work 2013, 44(2):117-132.

10. Anner J, Schwegler U, Kunz R, Trezzini B, de Boer W: Evaluation of work disability and the international classification of functioning, disability and health: what to expect and what not. BMC Public Health 2012, 12:470.

11. Körner M: ICF und sozialmedizinische Beurteilung der Leistungsfähigkeit im Erwerbsleben: Alles klar? - Ein Diskussionsbeitrag. Rehabilitation (Stuttg) 2005, 44(4):229-236.

12. Bürge $E$, Cieza $A$, Allet L, Finger ME, Stucki G, Huber EO: Intervention categories for physiotherapists treating patients with internal medicine conditions on the basis of the International Classification of Functioning Disability and Health. Int J Rehabil Res 2008, 31(1):43-50.

13. Jelsma J: Use of the International Classification of Functioning, Disability and Health: a literature survey. J Rehabil Med 2009, 41(1):1-12.

14. Hieblinger R, Coenen M, Stucki G, Winkelmann A, Cieza A: Validation of the International Classification of Functioning, Disability and Health Core Set for chronic widespread pain from the perspective of fibromyalgia patients. Arthritis Res Ther 2009, 11(3):R67.

15. Kirschneck $M$, Kirchberger I, Amann E, Cieza A: Validation of the comprehensive ICF core set for low back pain: The perspective of physical therapists. Man Ther 2011, 16(4):364-372.

16. Soer R, van der Schans CP, Geertzen JH, Groothoff JW, Brouwer S, Dijkstra PU, Reneman MF: Normative values for a functional capacity evaluation. Arch Phys Med Rehabil 2009, 90(10):1785-1794.

17. Homa DB: Using the International Classification of Functioning, Disability and Health (ICF) in job placement. Work 2007, 29(4):277-286.

18. Glässel A, Finger ME, Cieza A, Treitler C, Coenen M, Escorpizo R: Vocational rehabilitation from the client's perspective using the International Classification of Functioning, Disability and Health (ICF) as a reference. J Occup Rehabil 2011, 21(2):167-178.
19. Salvador-Carulla L, Garcia-Gutierrez C: The WHO construct of health-related functioning (HrF) and its implications for health policy. BMC Public Health 2011, 11(Suppl 4(11)):S9.

20. Duchan JF: Where is the person in the ICF? Advanc Speech-Language Pathol 2004, 6(1):63-65.

21. Wade DT, Halligan P: New wine in old bottles: the WHO ICF as an explanatory model of human behaviour. Clin Rehabil 2003, 17(4):349-354

22. Offenbächer M, Cieza A, Brockow T, Amann E, Kollerits B, Stucki G: Are the contents of treatment outcomes in fibromyalgia trials represented in the International Classification of Functioning, Disability, and Health? Clin J Pain 2007, 23(8):691-701

23. Cieza A, Stucki G, Weigl M, Kullmann L, Stoll T, Kamen L, Kostanjsek N, Walsh N: ICF Core Sets for chronic widespread pain. J Rehabil Med 2004, 36(Suppl 44):63-68.

24. Schult ML, Ekholm J: Agreement of a work-capacity assessment with the World Health Organisation International Classification of Functioning, Disability and Health pain sets and back-to-work predictors. Int J Rehabil Res 2006, 29(3):183-193.

25. Schwegler U, Peter C, Trezzini B, Anner J, Geyh S: Toward transparent documentation in medical work capacity evaluations: identifying personal factors in medical reports on Swiss disability claimants with chronic widespread pain. Int J Rehabil Res 2013, 36(4):298-307.

26. Fayed N, Cieza A, Bickenbach JE: Linking health and health-related information to the ICF: a systematic review of the literature from 2001 to 2008. Disabil Rehabil 2011, 33(21-22):1941-1951.

27. Schwegler U, Anner J, Boldt C, Glässel A, Lay V, De Boer WE, Stucki G, Trezzini B: Aspects of functioning and environmental factors in medical work capacity evaluations of persons with chronic widespread pain and low back pain can be represented by a combination of applicable ICF Core Sets. BMC Public Health 2012, 12(1):1088.

28. Cieza A, Stucki G, Weigl M, Disler P, Jäckel W, van der Linden S, Kostanjsek N, de Bie R: ICF Core Sets for low back pain. J Rehabil Med 2004, 36(44 Suppl):69-74.

29. Cieza A, Chatterji S, Andersen C, Cantista P, Herceg M, Melvin J, Stucki G, de Bie R: ICF Core Sets for depression. J Rehabil Med 2004, 36(Suppl 44):128-134.

30. Stucki A, Daansen P, Fuessl M, Cieza A, Huber E, Atkinson R, Kostanjsek N, Stucki G, Ruof J: ICF Core Sets for obesity. J Rehabil Med 2004, 36(Suppl 44):107-113.

31. Lee F, Peterson C: Content analysis of archival data. J Consult Clin Psychol 1997, 65(6):959-969.

32. Patton M: Qualitative evaluation and research methods. Newbury Park: Sage; 1990.

33. Coenen M: Developing a method to validate the WHO ICF Core Sets from the patient perspective: rheumatoid arthritis as a case in point. PhD thesis. In Munich: Ludwig-Maximilians-University; 2008.

34. Cieza A, Brockow T, Ewert T, Amman E, Kollerits B, Chatterii S, Üstün TB, Stucki G: Linking health-status measurements to the international classification of functioning, disability and health. J Rehabil Med 2002, 34(5):205-210.

35. Cieza A, Geyh S, Chatterji S, Kostanjsek N, Üstün B, Stucki G: ICF linking rules: an update based on lessons learned. J Rehabil Med 2005, 37(4):212-218

36. Kottner J, Audige L, Brorson S, Donner A, Gajewski BJ, Hrobjartsson A, Roberts C, Shoukri M, Streiner DL: Guidelines for Reporting Reliability and Agreement Studies (GRRAS) were proposed. J Clin Epidemiol 2011 64(1):96-106.

37. Geyh S, Cieza A, Bickenbach JE, Stucki G: ICF Personal Factors Preparatory Outline. Nottwil: ICF Research Branch; 2009.

38. Grotkamp SL, Cibis WM, Nüchtern EAM, von Mittelstaedt G, Seger WKF: Personal Factors in the International Classification of Functioning Disability and Health: Prospective Evidence. Aust J Rehabilitation Couns 2012, 18(1):1-24.

doi:10.1186/1472-6963-14-361

Cite this article as: Schwegler et al:: Towards comprehensive and transparent reporting: context-specific additions to the ICF taxonomy for medical evaluations of work capacity involving claimants with chronic widespread pain and low back pain. BMC Health Services Research 2014 14:361 